\title{
Short Term Caco-2/TC7 Cell Culture: Comparison between of Conventional 21-d and a Commercially Available 3-d System
}

\author{
Georges Da Violante, ${ }^{a}$ Naima Zerrouk, ${ }^{a}$ Isabelle Richard,${ }^{b}$ Jean-Louis Frendo, ${ }^{c}$ Azzédine Zhiri, ${ }^{b}$ \\ René Li-Khuan, ${ }^{d}$ Viviane Tricottet,${ }^{d}$ Gérard Provot, ${ }^{b}$ Jean-Claude Chaumeil,${ }^{a}$ and \\ Philippe ARNAUD $*, d$ \\ ${ }^{a}$ Laboratoire de Pharmacie Galénique, UPRES EA 2498, Faculté des Sciences Pharmaceutiques et Biologiques, \\ Université René Descartes; 75006 Paris, France: ${ }^{b}$ Laboratoire GlaxoSmithKline, New Chemical Entity Unit; 23, rue \\ Lavoisier, ZI $n^{\circ} 2$ La Madeleine, 27091 Evreux Cedex 9, France: ${ }^{c}$ Développement humain, croissance et differenciation, \\ INSERM U427, Faculté des Sciences Pharmaceutiques et Biologiques, Université René Descartes; 75006 Paris, France: \\ ${ }^{d}$ Service commun de microscopie électronique, Faculté des Sciences Pharmaceutiques et Biologiques, Université René \\ Descartes; 75006 Paris, France: and ${ }^{e}$ Laboratoire de Pharmacie Galénique, ADEN EA 3234, Faculté de Médecine et de \\ Pharmacie, Université de Rouen; 76183 Rouen, France. $\quad$ Received November 28, 2003; accepted June 17, 2004
}

The Caco-2 cell model is a valuable tool for studying intestinal biotransformation of xenobiotics and to evaluate the potential of human intestinal absorption of new compounds. These properties were evaluated with Caco-2/TC7 cells in accelerated conditions to reduce maturation lag time from 21-d to 3-d in order to increase time and labor efficiency. Transmission electron and fluorescent microscopy were used for morphological characterization. Alkaline phosphatase and lactate dehydrogenase activities were assessed within time. Cytochrome P450 expression was studied by RT-PCR. Apparent permeabilities of a set of passively absorbed molecules across Caco-2/TC7 cell monolayers were determined to evaluate potential of both systems for prediction of human intestinal absorption. Microscopic images revealed that cells under both conditions differentiated as enterocyte-like cells but did so heterogeneously in the 3-d model. TEER values have shown that the 3-d model is a leakier cell system with higher mannitol Papp $(\mathrm{cm} / \mathrm{s})$. Biochemical characterization (hydrolase activities, CYP450 expression) suggested that the 3-d model was at a lower maturation level than the 21-d model. Carrier-mediated uptake of L-Phe was lower in the 3-d model suggesting that this model has limited application for mechanistic studies. Reasonable correlation was obtained between the two models $\left(r^{2}=0.88, p>0.01\right)$ for 11 passively absorbed compounds with high potential of rank ordering of compounds. Although results suggested that the 3-d cells are under-differentiated, they could be usable to estimate the oral absorption of passively absorbed compounds.

Key words Caco-2/TC7; apparent permeability; morphology; phosphatase alkaline; lactate dehydrogenase; CYP450

Selection of drug candidates that are highly permeable across human intestinal epithelium and resistant to first-pass metabolism is an important step in oral drug development. In vitro permeation assays with cultured enterocyte-like cells are routinely used in the pharmaceutical industry for the prediction of human intestinal absorption in the early drug discovery process. ${ }^{1-4)}$ Cultured Caco-2 cells are described in the literature as the reference model to study intestinal drug absorption. The parental Caco-2 cell line exhibits characteristics close to epithelial cells from ileum in spite of their colonic origin. Engle et al. ${ }^{5)}$ indicate that the parental Caco-2 cell line heterogeneously differentiates due to different cell populations (enterocytes and colonocytes) present in the same culture. In addition, the cytochrome $3 \mathrm{~A}$ family, responsible for metabolism of more than $50 \%$ of orally administered drugs, is lacking in the parental cell line which has limits its application. ${ }^{6,7)}$ Different authors reported that the Caco-2 clone TC7 cell line, obtained from high passages, is a suitable model for the evaluation of the role of small intestine in the absorption and biotransformation of drugs by displaying, (i) higher taurocholic acid transport activity, (ii) higher brush-border associated hydrolase sucrase-isomaltase activity, and (iii) higher cytochrome $3 \mathrm{~A}$ activity. ${ }^{6-8)}$ In addition, high potential for rank ordering compounds and prediction of human intestinal absorption was found using the TC7 clone. ${ }^{4)}$ However, the differentiation of Caco-2 cells required a long culture period (21-d) with daily medium change. ${ }^{4,9)}$

Accelerated in vitro Caco-2 permeation assays were devel- oped to decrease time and cost and to increase labor efficiency to meet the requirement of high through-put screening in selecting new drug candidates. ${ }^{9-12)}$ Among a number of ways of accelerating the growth environment for Caco-2 cell culture, a commercially available culture environment kit composed of well-standardized serum-free culture media and coated inserts from Becton Dickinson (Biocoat ${ }^{\circledR}$ Intestinal Epithelium Differentiation Environment) is able to reduce the maturation of parental Caco-2 cells from 21 to 3-d..$^{9,12)}$ Using this standard serum-free media, the accelerated environment provides leakier Caco-2 cell monolayers than the conventional long-term Caco-2 systems with higher paracellular permeability. ${ }^{9)}$ The use of monolayers with high cell-to-cell tightness leads to an under-estimation of the fraction absorbed of paracellular permeable compounds. ${ }^{13)}$ Cell monolayers with low resistance to passive ion diffusion are reported to increase the potential of predicting of intestinal absorption of these compounds. ${ }^{9)}$ However, by increasing the paracellular permeability, the ratio between high and low permeable compounds is lower, reducing the potential of rank ordering compounds using such 3-d models. ${ }^{11)}$ Yamashita et al. ${ }^{12)}$ suggested that using fetal calf serum (FCS) $(10 \% \mathrm{v} / \mathrm{v})$ with short-term cultures results in tighter cell monolayers. These authors showed a comparable rank ordering of compounds to long term Caco- 2 cultures. However, the use of FCS may result in intra- and inter-laboratory variabilities since, as the FCS has an undefined composition, there is a risk of lot to lot variability. ${ }^{10)}$ 
The aim of this work was to evaluate the potential of using the clone TC7 cultured as short term cultures in order to study the human intestinal absorption of new active compounds. Firstly, we presented a comparison between the accelerated 3-d Biocoat ${ }^{\circledR}$ model using serum-free Caco-2/TC7 cells and the conventional $21-\mathrm{d}$ model in their ability to form well differentiated enterocyte-like cells morphologically and biochemically. In addition, we evaluated the potential of using this 3-d model for the prediction of oral absorption of compounds actively or passively transported across the intestinal mucosa.

\section{MATERIALS AND METHODS}

Chemicals Caffeine, testosterone, sulfadiazine, acetaminophen, atenolol, propranolol, clonidine, terbutaline were obtained from Sigma (St Quentin Fallavier, France). Radiolabelled $\left[{ }^{14} \mathrm{C}\right] \mathrm{mannitol}$ (spec. act. $45-60 \mathrm{mCi} / \mathrm{mmol}$ ), $\left[{ }^{3} \mathrm{H}\right]$ testosterone (spec. act. $100-180 \mathrm{Ci} / \mathrm{mmol}$ ), $\left[{ }^{3} \mathrm{H}\right]$ inuline (spec. act. $100-500 \mathrm{mCi} / \mathrm{g}$ ), [ $\left.{ }^{3} \mathrm{H}\right] \mathrm{PEG} 900$ (spec. act. 2$10 \mathrm{mCi} / \mathrm{g}$ ) and $\left[{ }^{14} \mathrm{C}\right] \mathrm{L}-\mathrm{Phe}$ (spec. act. $450 \mathrm{mCi} / \mathrm{mmol}$ ) were purchased by New England Nuclear (Les Ulis, France). All culture media were provided by Life Technologies (Eragny, France). The 3-d model kit BIEDE consists of pre-coated inserts of polyethyleneterephtalate (diameter $24 \mathrm{~mm}$, porosity $1 \mu \mathrm{m})$. Basal Seeding Medium ${ }^{\mathrm{TM}}$ (BSM), EnteroSTIM ${ }^{\mathrm{TM}}$ (ES) and $\mathrm{MITO}+{ }^{\mathrm{TM}}$ serum extender were purchased from Becton Dickinson (Le Pont de Claix, France). Microporous membranes of polyester Transwell-Clear ${ }^{\circledR}$ (diameter $24 \mathrm{~mm}$; porosity $0.4 \mu \mathrm{m}$ ) were obtained from Corning Costar (D. Dutcher, Brumath, France). All other chemicals were analytical grade.

Cell Culture Caco-2/TC7 cells were kindly provided by Dr. A. Sweibaum and Dr. M. Rousset (INSERM, U170, Villejuif, France) at passage 8 . Cells $\left(0.5 \times 10^{6}\right)$ were seeded on $75 \mathrm{~cm}^{2}$ plastic flasks (Corning Costar) and changed every other day with a complete medium containing Dulebcco's Modified Eagle's Medium (DMEM) supplemented by $10 \%$ of FCS and $1 \%$ of non essential aminoacids. Caco-2/TC7 cells were incubated in a controlled atmosphere at $37^{\circ} \mathrm{C}$, $95 \%$ relative humidity, $10 \% \mathrm{CO}_{2}$ and allowed to reach confluence for $7 \mathrm{~d}$. For transport studies, cells were seeded onto Transwell-Clear $^{\circledR}\left(4.71 \mathrm{~cm}^{2}\right)$ and Biocoat ${ }^{\circledR}\left(4.19 \mathrm{~cm}^{2}\right)$ inserts. The Transwell-Clear ${ }^{\circledR}$ and Biocoat inserts were seeded, respectively, at the density of $1.5 \times 10^{6}$ and $2.0 \times 10^{6}$ cells per filter. The cells were allowed to grow and differentiate up to $28 \mathrm{~d}$ in complete medium supplemented with penicillin $(110 \mathrm{UI} / \mathrm{ml})$ and streptomycin $(110 \mu \mathrm{g} / \mathrm{ml})$ in the conventional model. Caco-2/TC7 cells in the $3-\mathrm{d}$ model were grown in BSM (serum free DMEM) supplemented by MITO $+{ }^{\mathrm{TM}}$ serum extender (EGF, transferrin, insulin, ECGS, triiodothyronine, hydrocortisone, progesterone, testosterone, oestradiol-17 $\beta$, selenium and $o$-phosphorylethanolamine) for $24 \mathrm{~h}$, and by ES (butyric acid containing serum free DMEM) supplemented by MITO $+{ }^{\mathrm{TM}}$ serum extender every other day for $7 \mathrm{~d}$.

Morphological Comparison Electron Microscopy: Caco-2/TC7 cells at passage 22 and 24, respectively, for 21-d and $3-d$ cell monolayers were used for ultrastructure comparison. At 21 and 3-days, in 21-d and 3-d cell monolayers, cells were rinsed twice in phosphate buffer salt solution (PBS), and fixed in glutaraldehyde $2.5 \% \mathrm{vol} / \mathrm{vol}$ in PBS. They were then treated as described elsewhere for transmission electron microscopy (TEM) using a JEOL JEM-100S. ${ }^{10)}$

Fluorescent Microscopy (FM): Cell nuclei were observed, respectively, at 3 and $21 \mathrm{~d}$ in the $3-\mathrm{d}$ and $21-\mathrm{d}$ models by DAPI fluorescent dye coloration, then observed in a fluorescent microscope OLYMPUS BX2.

Trans-epithelial Electrical Resistance (TEER): TEER values of filter-grown 3-d and 21-d cells in appropriate culture medium at $37^{\circ} \mathrm{C}$ were measured at certain times by an epithelial volt-ohmmeter fitted with planar electrodes (Millicell-ERS, Millipore, France) to check the monolayer's confluence and integrity. The TEER values were calculated according to the following equation:

$\operatorname{TEER}\left(\Omega \cdot \mathrm{cm}^{2}\right)=\left(R_{\text {total }}-R_{\text {filter w/o cells }}\right) \times A$

where $R_{\text {total }}$ is the resistance measured $(\Omega), R_{\text {filter }}$ w/o cells $(\Omega)$ is the resistance of inserts alone and $A$ is the surface area $\left(\mathrm{cm}^{2}\right)$.

Enzyme Activity Activities of alkaline phosphatase (ALP) were determined using $p$-nitrophenylphosphate as substrate. ${ }^{14)}$ Briefly, cell homogenates were obtained by scraping the cells from each insert at various time intervals on both models after incubation with an aqueous solution containing Triton ${ }^{\circledR} \times 100(1 \% \mathrm{w} / \mathrm{v})$, and Complete ${ }^{\circledR}$ Mini solution (Protease inhibitor cocktail, Boehringer Mannheim, Germany) for 1 -h at room temperature. Sonication was performed at $20 \%$ of maximal power for $20 \mathrm{~s}$ in ice (Sonifier $^{\mathrm{TM}}$ 450, Branson, U.S.A.). Lactate dehydrogenase (LDH) activities were obtained using the cytotoxicity LDH kit (Roche Diagnostics, Meylan, France). Total protein contents were determined by the Biorad assay using bovine serum albumin as standard protein. ${ }^{15)}$

Expression of Cytochromes P450 Caco-2/TC7 cells were cultured as described above for 21 and $3-\mathrm{d}$. Total RNA was isolated from two different inserts $\left(4-5 \times 10^{6}\right.$ cells) using Trizol ${ }^{\circledR}$ reagent as recommended by Life Technologies (Eragny, France). Then, RT-PCR experiments were conducted according to Raeissi et al. ${ }^{7)}$ Briefly, cDNA was synthesized using $1 \mu \mathrm{g}$ total mRNA, $30 \mathrm{pmol}$ oligo $\mathrm{T}$ (12$18 \mathrm{bp}$ ), Superscript ${ }^{\circledR}$ RT (MMLV), $50 \mathrm{U}$ Taq polymerase, and dNTP's. The PCR for CYPs 1A1, 3A4, 3A5 and actin were performed in PCR buffer containing $3 \mathrm{~mm} \mathrm{MgCl}_{2}$, dNTP's and 30 pmol primers according to the following: $5 \mathrm{~min} 94^{\circ} \mathrm{C}$, 30 cycles of $15 \mathrm{~s}$ at $94^{\circ} \mathrm{C}, 15 \mathrm{~s}$ at $55^{\circ} \mathrm{C}, 45 \mathrm{~s}$ at $72^{\circ} \mathrm{C}$ each and $10 \mathrm{~min}$ at $72{ }^{\circ} \mathrm{C}$. The primers and RT-PCR products were obtained by Life Technologies (Eragny, France).

Amino Acid Transport Expression Uptake experiments were performed in each model according to Hidalgo and Borchardt. ${ }^{16)}$ Cell monolayers were incubated for $5 \mathrm{~min}$ with a solution containing radiolabelled $\left[{ }^{14} \mathrm{C}\right] \quad$ L-Phe $(0.5 \mu \mathrm{Ci} / \mathrm{ml})$ and unlabelled L-Phe, $0.2 \mathrm{~mm}$ and $2 \mathrm{~mm}$, respectively, presented in the apical (AP) or basolateral (BL) side of the monolayers. After incubation cell monolayers were washed three times in ice-cold Hank's balanced salt solution (HBSS) and $1.5 \mathrm{ml}$ of a cell digestion solution containing Triton $\times 100(0.1 \% \mathrm{w} / \mathrm{v})$ in $\mathrm{NaOH}(0.3 \mathrm{~N})$ was added. Following incubation overnight at room temperature, the cells were scraped and incubated at $37^{\circ} \mathrm{C}$ for $30 \mathrm{~min}$ for better homogenization. Five hundred microliters of the homogenate was analyzed by liquid scintillation counting for the amount of 
solute taken up. The total amount of protein was determined and uptake was expressed as \% transported L-Phe/mg protein $/ 5 \mathrm{~min}$.

Transport Studies The transport medium was modified HBSS containing $25 \mathrm{~mm}$ HEPES, pH 7.4 at $37^{\circ} \mathrm{C}$. TEER of cell monolayers was measured before and after each experiment to control the cell monolayer integrity. Cell monolayers with TEER less than 300 and $500 \Omega \cdot \mathrm{cm}^{2}$, respectively, for the 3-d and 21-d models were not used for transport studies. The transport studies were initiated by adding $1.5 \mathrm{ml}$ of fresh buffer with mannitol $(0.2 \mu \mathrm{Ci} / \mathrm{ml})$ as hydrophilic marker of junctional integrity to the apical compartment; then, $2.5 \mathrm{ml}$ of fresh buffer was replaced in the basolateral side. At time zero, working solutions were withdrawn for quantification of initial counts in case of radiolabelled scintillation counting in the donor solution. The cell monolayers were incubated at $37^{\circ} \mathrm{C}$ under controlled atmosphere without shaking for up to 120-min. At 30-min intervals, samples $(1 \mathrm{ml})$ were taken from each receiver compartment and immediately replaced by fresh HBSS/HEPES (25 mm) pH 7.4.

Apical to basolateral apparent permeabilities (Papp) were calculated according to Eq. 2:

$$
\operatorname{Papp}(\mathrm{cm} / \mathrm{s})=\left(\frac{d Q}{d t}\right) \times\left(\frac{1}{A \cdot C o}\right)
$$

where $d Q / d t$ is the flux of drug across the cell monolayer $(\mathrm{mol} / \mathrm{s}), C o$ is the initial concentration in the donor compartment $(\mathrm{mol} / \mathrm{ml})$, and $A$ is the surface area of the cell monolayer $\left(\mathrm{cm}^{2}\right)$. The apparent permeability values were expressed as $\mathrm{cm} / \mathrm{s}$.

Analytical Methods The concentrations of radiolabelled compounds were determined by liquid $\beta$-scintillation counting with quench correction according to single or dual label mode (Beckman LS 3801, Beckman). The concentrations of non radiolabelled drugs were analyzed by a HPLC-UV assay. An Uptisphere ${ }^{\mathrm{TM}} \mathrm{C} 18$ reverse phase column $(100 \times 4.6 \mathrm{~mm}$; porosity $3 \mu \mathrm{m}$ ) was used. Flow rates were $1 \mathrm{ml} / \mathrm{min}$ for each compound tested. The mobile phase and wavelength of detection were dependent on the compound quantified. The mobile phase and wavelength for caffeine and acetaminophen were $\mathrm{ACN} /$ water (13/87) and (10/90) at 273 and $245 \mathrm{~nm}$ respectively. Mobile phases and wavelengths for atenolol, propranolol, terbutaline were $\mathrm{ACN} / \mathrm{KH}_{2} \mathrm{PO}_{4} 10 \mathrm{~mm}$ (8/92), (30/70), (6/94) at 223, 287 and $220 \mathrm{~nm}$, respectively. Mobile phases and wavelength for clonidine and sulfadiazine were $\mathrm{ACN} / \mathrm{KH}_{2} \mathrm{PO}_{4} 50 \mathrm{~mm}(10 / 90)$ at 225 and $265 \mathrm{~nm}$, respectively.

\section{RESULTS}

Monolayer Confluence and Integrity TEM examination of Caco-2 cell monolayers has shown that the 21-d cell monolayers had the characteristics of well-differentiated columnar cells with tight junctions and important microvilli expression organised as a brush border (Fig. 1A). In addition, FM (Fig. 1B) indicated that cell nuclei is homogeneous throughout the cell monolayer with a diameter of approximately $13 \mu \mathrm{m}$. In the $3-\mathrm{d}$ model, cells differentiated in polarised monolayers with apparent tight junctions (Fig. 1C). Sparse microvilli are expressed in the apical membrane of
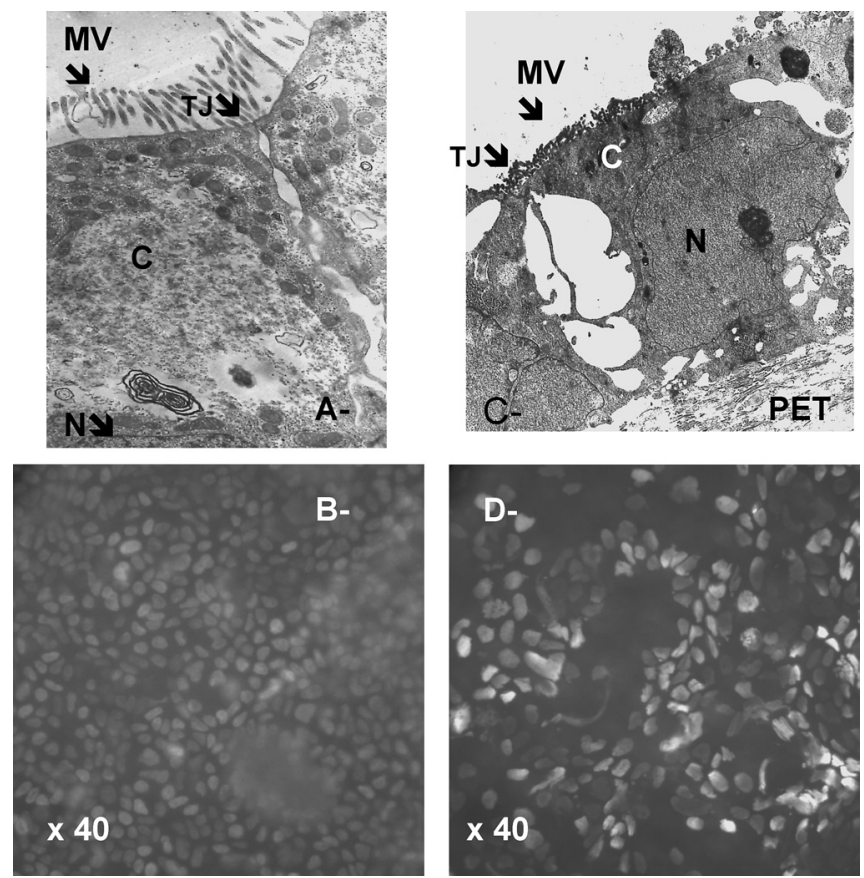

Fig. 1. Images of Transmission Electron and Fluorescence Microscopy of 3-d (A, B) and 3-d (C, D) Caco-2/TC7 Cells

Microvilli (MV); cytosol (C); nucleus (N); tight junctions (TJ); polyethyleneterephtalate filter (PET)

3 d-old cells without a packed brush border. Lateral intercellular spaces appeared quite tortuous and large (Fig. 1C). The width of $3 \mathrm{~d}$-old cells was approximately $15-20 \mu \mathrm{m}$ whereas it was $10-15 \mu \mathrm{m}$ for the $21-\mathrm{d}$ cells (Figs. 1A, C). FM images have shown that cell nuclei were heterogeneous in size and aspect in the 3-d model with a diameter of approximately $17 \mu \mathrm{m}$ (Fig. 1D).

Resistance to passive ion transport represented by TEER measurement and the apparent permeability of the hydrophilic mannitol are the reflection of integrity, tightness and confluence of cell monolayers. Results of TEER and mannitol Papp $(\mathrm{cm} / \mathrm{s})$ are reported in Table 1. On the 21-d model, TEER values increased up to $14 \mathrm{~d}$ and remained not statistically different (ANOVA, $p>0.05$ ) up to $28 \mathrm{~d}$. The $3-\mathrm{d}$ model exhibited TEER values which increased quickly up to 3-d and remained not statistically different up to 5-d (ANOVA, $p>0.05$ ). After the 5th day, TEER values decreased significantly from $455 \pm 138$ to $141 \pm 81 \Omega \cdot \mathrm{cm}^{2}$ at $7 \mathrm{~d}$ (ANOVA, $p<0.05$ ). In addition, the TEER values determined at $3 \mathrm{~d}$ were statistically lower $(p<0.05)$ than those measured at $21-\mathrm{d}$ for the conventional model, respectively $468 \pm 103$ and $711 \pm 79 \Omega \cdot \mathrm{cm}^{2}$. Mannitol apparent permeability values within time correlated well $\left(r^{2}=0.98 ; p<0.05\right)$ with the TEER values in the $21-\mathrm{d}$ model. When TEER values increased, the mannitol Papp $(\mathrm{cm} / \mathrm{s})$ values decreased to remain relatively stable from 21 to 28 -old day monolayers, i.e. the mannitol Papp $(\mathrm{cm} / \mathrm{s})$ is equal to $0.07 \pm 0.01$ and $0.10 \pm 0.01$, respectively, at 21 and $28 \mathrm{~d}$. In contrast, the TEER values measured in the 3-d model were not correlated with the mannitol Papp $(\mathrm{cm} / \mathrm{s})$ values from seeding date to $7 \mathrm{~d}$. Actually, from cell seeding to the 3rd day, the TEER values and the apparent permeability of mannitol were not correlated $(p>0.05)$ whereas a linear correlation $\left(r^{2}=0.99 ; p<0.05\right)$ was obtained from the 3 rd day to the 7 th day. In addition, the 
Table 1. Comparison of Apparent Permeability Values of Mannitol and TEER Values in a Certain Period between the Accelerated 3-d and Conventional 21-d Caco-2/TC7 Culture Cells

\begin{tabular}{|c|c|c|c|c|c|}
\hline \multicolumn{3}{|c|}{ 3-d mode } & \multicolumn{3}{|c|}{ 21-d model } \\
\hline Time (d) & $\operatorname{TEER}\left(\Omega \cdot \mathrm{cm}^{2}\right)$ & Mannitol $\left(\mathrm{P} a p p \times 10^{-6} \mathrm{~cm} / \mathrm{s}\right)$ & Time $(\mathrm{d})$ & $\operatorname{TEER}\left(\Omega \cdot \mathrm{cm}^{2}\right)$ & Mannitol $\left(\mathrm{Papp} \times 10^{-6} \mathrm{~cm} / \mathrm{s}\right)$ \\
\hline to (filter alone) & - & $39.09 \pm 2.57$ & to (filter alone) & - & $44.19 \pm 2.10$ \\
\hline 2 & $337 \pm 79$ & $13.87 \pm 2.54$ & 7 & $570 \pm 82$ & $0.44 \pm 0.08$ \\
\hline 3 & $468 \pm 103$ & $0.61 \pm 0.18$ & & & \\
\hline 4 & $512 \pm 115$ & $0.81 \pm 0.15$ & 14 & $651 \pm 62$ & $0.13 \pm 0.01$ \\
\hline 5 & $455 \pm 138$ & $1.20 \pm 0.26$ & & & \\
\hline 6 & $313 \pm 91$ & $1.96 \pm 0.27$ & 21 & $711 \pm 79$ & $0.07 \pm 0.01$ \\
\hline 7 & $141 \pm 81$ & $3.19 \pm 0.74$ & 28 & $671 \pm 67$ & $0.10 \pm 0.01$ \\
\hline
\end{tabular}

Each value is the mean \pm S.D. of $n=6$ independent experiments.

Table 2. Enzymatic Activities of Alkaline Phosphatase and Lactate Dehydrogenase on 3-d and 21-d Caco-2/TC7 Culturing Conditions

\begin{tabular}{|c|c|c|c|c|}
\hline & \multicolumn{2}{|c|}{ 21-d model } & \multicolumn{2}{|c|}{ 3-d model } \\
\hline & $21 \mathrm{~d}$ & $28 d$ & $3 \mathrm{~d}$ & $5 \mathrm{~d}$ \\
\hline ALP (mUI/mg prot) & $169.4 \pm 9.5$ & $92.2 \pm 21.1$ & $6.4 \pm 0.9$ & $304.4 \pm 4.7$ \\
\hline Total LDH (UI/mg prot) & $9.1 \pm 1.6$ & $11.4 \pm 6.4$ & $0.89 \pm 0.28$ & $0.43 \pm 0.10$ \\
\hline
\end{tabular}

Each value is the mean \pm S.D. of $n=3$ independent experiments.

mannitol Papp (cm/s) across the short-term model at 3-d was higher than in the 21-d model by 9-fold (ANOVA, $p<0.05$ ).

Alkaline Phosphatase and Lactate Dehydrogenase Activities Table 2 summarises the enzyme activities determined for a period in both models of two enzymes (ALP and LDH). In the 21-d model, the brush border ALP enzyme activity was $169.4 \pm 9.5$ and $92.2 \pm 21.1 \mathrm{mUI} / \mathrm{mg}$ of total protein, respectively, at 21 and $28-\mathrm{d}$. The ALP activity values in the 3-d model were, respectively, $6.4 \pm 0.9$ to $304.4 \pm$ $4.7 \mathrm{mUI} / \mathrm{mg}$ of total protein after 3 and $5 \mathrm{~d}$. ALP activity was thus almost 25-fold higher with 21-old day cells in the 21-d model compared with 3-old day cells in the 3-d model. The measured LDH activity values in the 21-d model were constant between 21 and $28 \mathrm{~d}$ (ANOVA, $p>0.05$ ), respectively, $9.1 \pm 1.6$ and $11.4 \pm 6.4 \mathrm{mUI} / \mathrm{mg}$ of total protein. The shortterm cells exhibited LDH activities stable from 3 and $5 \mathrm{~d}$ (ANOVA, $p>0.05$ ), respectively, $0.89 \pm 0.28$ and $0.43 \pm 0.1 \mathrm{mUI} / \mathrm{mg}$ prot. The LDH activity exhibited by the 21-d model was almost 10-fold higher than in the 3-d model.

Cytochrome P450 Expression The presence of three major cytochromes $\mathrm{P} 450$ of human intestine responsible for the metabolism of numerous drugs, CYP1A1, 3A4 and 3A5, was checked using the RT-PCR technique in cells cultured for 3 or $21 \mathrm{~d}$ depending on each model. As demonstrated by the presence of specific bands at 430,470 and $360 \mathrm{bp}$, respectively, for CYP 1A1, 3A4, and 3A5 both Caco-2/TC7 cell models were found to express the mRNA of those cytochromes (Fig. 2). Although this method is qualitative rather than quantitative, the expression of mRNA for each cytochrome could be compared on the models by using actin as reference signal (Fig. 2). CYP1A1, and 3A5 mRNA were expressed at the same degree on both systems, CYP3A4 expression was found lower in the 3-d model.

Amino Acid Transport Expression The AP and BL uptake of the L-Phe by Caco- 2 cells cultured under both culturing conditions are shown in Fig. 3. The results were expressed as the percentage of initial dose of L-Phe by amount

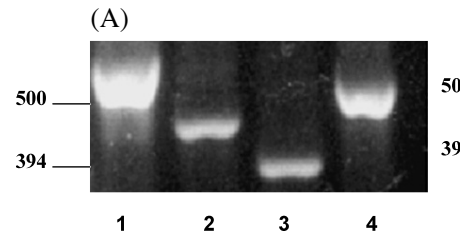

(B)

Fig. 2. Qualitative Expression of mRNAs for Three CYPs in 21-d (A) and 3-d (B) Caco-2/TC7

A and B: actin (lane 1), CYP1A1 (lane 2), CYP3A4 (lane 3), CYP3A5 (lane 4).

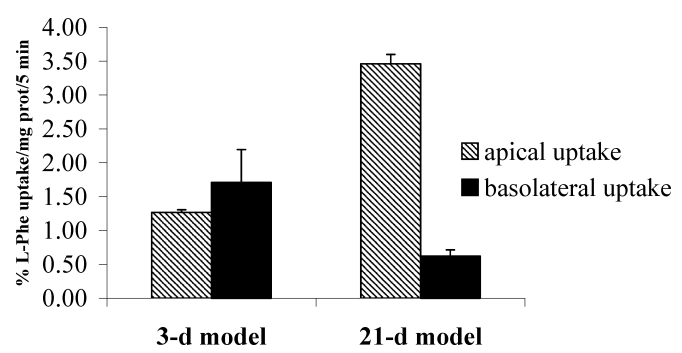

Fig. 3. AP and BL Uptake of L-Phe on Conventional 21-d and Accelerated 3-d Caco-2/TC7 Cell Cultures

Initial AP and BL concentrations were respectively $2 \mathrm{~mm}$ and $0.2 \mathrm{~mm}$. Bars indicate the mean \pm S.D. of three independent wells.

of total protein $(\mathrm{mg})$ for $5 \mathrm{~min}$ incubation time (Fig. 3). The AP and BL uptake of L-Phe obtained for the 21-d model were $3.46 \pm 0.14$ and $0.6 \pm 0.1 \%$ transport $/ \mathrm{mg}$ prot $/ 5 \mathrm{~min}$ respectively with a ratio $\mathrm{AP} / \mathrm{BL}$ close to 6 . This $\mathrm{AP} / \mathrm{BL}$ polarization suggested the presence of a carrier-mediated uptake. The AP and BL uptake exhibited by the 3 -d cells was, respectively, $1.30 \pm 0.04$ and $1.7 \pm 0.5 \%$ transport $/ \mathrm{mg} \operatorname{prot} / 5 \mathrm{~min}$. Even these results were not statistically different and were not consistent with an active transport of the L-Phe (ANOVA, $p>0.05)$. In addition, the AP uptake was statistically lower by 2-fold in the 3-d model compared with the 21-d system whereas the BL uptake was higher by 3 -fold.

Prediction of Human Intestinal Absorption The predictive potential of human intestinal absorption of each 
Table 3. List of Drugs Evaluated with the 3-d and the 21-d Models

\begin{tabular}{lccc}
\hline \hline Compound & $\begin{array}{c}\text { Oral absorption } \\
\text { in humans }\end{array}$ & $\begin{array}{c}21-\mathrm{d} \mathrm{Papp} \\
\left(\times 10^{-6} \mathrm{~cm} / \mathrm{s}\right)\end{array}$ & $\begin{array}{c}3-\mathrm{d} \mathrm{Papp}{ }^{b)} \\
\left(\times 10^{-6} \mathrm{~cm} / \mathrm{s}\right)\end{array}$ \\
\hline Caffeine & 100 & $46.80 \pm 0.77$ & $48.20 \pm 1.74$ \\
Testosterone & 100 & $16.30 \pm 0.28$ & $20.90 \pm 0.4$ \\
Clonidine & 95 & $41.90 \pm 0.78$ & $45.10 \pm 0.51$ \\
Propranolol & 90 & $30.10 \pm 1.01$ & $35.00 \pm 0.91$ \\
Acetaminophen & 80 & $29.10 \pm 0.64$ & $28.20 \pm 1.57$ \\
Sulfadiazine & 65 & $12.10 \pm 0.40$ & $9.31 \pm 0.76$ \\
Terbutaline & 60 & $\left.\mathrm{nd}^{c}\right)$ & $2.32 \pm 0.38$ \\
Atenolol & 50 & $0.40 \pm 0.02$ & $3.02 \pm 2.07$ \\
Mannitol & 16 & $0.07 \pm 0.01$ & $0.61 \pm 0.18$ \\
PEG 900 & 10 & $0.57 \pm 0.07$ & $1.44 \pm 0.46$ \\
Inuline & 0 & $0.48 \pm 0.08$ & $1.54 \pm 0.29$ \\
\hline
\end{tabular}

a) Data from the literature. b) Each value is the mean \pm S.D. of $n=4-6$ independent experiments. c) Not detected.

model was checked by determining the apparent permeability values obtained from a heterogeneous series of passively absorbed compounds with a wide range of absorption $(0-$ $100 \%$ ) (data from the literature). The apparent permeability values of the tested compounds are summarized in Table 3. No marked differences were found in the apparent permeability values measured on both systems for compounds with human fraction absorbed above 65\% (e.g., acetaminophen, caffeine, clonidine, propranolol, sulfadiazine, testosterone). The apparent permeability values obtained across the 3-d model were increased for low permeable compounds which passage occurred mainly by the paracellular route. The Papp $(\mathrm{cm} / \mathrm{s})$ values for atenolol, inuline, mannitol, and PEG 900 were increased by 8, 5, 3 and 3-fold in the 3-d model.

\section{DISCUSSION}

The use of confluent monolayers of cultured cells for studying the intestinal absorption of new molecular entities has been widely used in academic as well as industrial laboratories. Validation criteria of these systems include: (i) morphological characterization with TEER measurement and permeability of hydrophilic markers to measure the cell monolayer confluence and integrity; (ii) expression of metabolic equipment (membrane hydrolases, cytochrome expression); (iii) evaluation of marker molecules for appropriate carriers; and (iv) establishment of an in vivo/in vitro correlation for compounds with passive diffusion. ${ }^{17)}$

The morphological aspects of the conventional 21-d Caco2/TC7 were in agreement with those obtained by other workers. ${ }^{4,8}$ Cells cultured for $21 \mathrm{~d}$ differentiated in a single monolayer of polarized enterocyte-like cells with apical brush border, cell-to-cell tight junctions and basolateral membrane adherent to the support. Furthermore, the presence of a homogeneous cell population in its morphological aspect was shown by ultrastructure analysis suggesting that most TC7 cells were at the same degree of differentiation (Fig. 1). As described previously, ${ }^{4,8,18)}$ these characteristics highlighted the TC7 clone as a suitable model for permeation assays but required a time-consuming and costly culture period.

High levels of growth factors added in the culture media (e.g., EGF, insulin, progesterone, butyric acid) reduce maturation from 21 to $3 \mathrm{~d}^{9-12)}$ Our observations showed that incomplete cell differentiation occurred with heterogeneous cell aspect and dimension, poor apical microvilli and important intercellular spaces by culturing TC7 cells with the standard Biocoat ${ }^{\circledR}$ serum-free culture media. These results indicated that the 3-d model is underdifferentiated compared with the 21-d model and even these images did not allow us to conclude whether cells are at different maturation levels or whether they expressed various phenotypes as described for other cell lines (e.g., parental Caco-2 cell line). ${ }^{15)}$

TEER values and apparent permeability of mannitol are usually checked to determine when cells are usable for transport studies. Actually, the 21-d model is usable for at least $14 \mathrm{~d}$ between the 14th and the 28th days in culture when mannitol and TEER remain constant. In most studies, cells are used between the 21 st and 28th day of culture because the biochemical aspect is taken into account. ${ }^{4,18)}$ In contrast, our findings suggested that short-term cultures can only be used for transport studies between the 3rd and the 4th day of culture (Table 1). Actually, low TEER values and high mannitol Papp $(\mathrm{cm} / \mathrm{s})$ may be related to incomplete monolayer formation with partial insert recovery. After the 3rd day, the monolayers are confluent, the decrease of TEER parallel with a slight increase of mannitol Papp $(\mathrm{cm} / \mathrm{s})$ is probably due to the looseness of tight junctions relative to the culture's age. These results were not consistent with a previous work indicating that the $3-\mathrm{d}$ model can provide a reproducible tool to perform transport studies between the 3rd and 7 th days. ${ }^{9)}$ On the other hand, Yamashita et al. ${ }^{12)}$ described a comparable phenomenon in TEER values with a decrease from the 5th day for parental Caco-2 short term cultures. These authors suggested that the use of butyric acid which induces differentiation may also increase apoptosis by down regulating the apoptosis-inhibitors (Bcl2 and Bcl-X1). Since in our study the Papp $(\mathrm{cm} / \mathrm{s})$ values of mannitol were not dramatically increased from 5 th to 7 th day of culture, it can be suggested that only a part of the cells started apoptosis. Indeed, this phenomenon resulted in a decrease of TEER and a slight increase in mannitol membrane permeability. Thus, since the 3-d model has been developed to increase labor efficiency, the use of short term cultures for only $2 \mathrm{~d}$ could limit its application for reducing flexibility in regard to scheduling experiments.

The cytochrome P450 gene superfamily encodes monooxygenases playing a major role in the metabolism of xenobiotics. In the human small intestine, the major P-450s found belong to the CYP3A and include the CYP3A4 and CYP3A5. ${ }^{6}$ However, the parental cell line does not express CYP3A4 as described by Raeissi et al. ${ }^{7)}$ whereas it is exhibited by TC 7 cells. Collett et al. ${ }^{13)}$ suggested the usefulness of the clone TC7 since it is usable to evaluate the first pass metabolism of orally administered compounds. In our study, similar results were obtained by showing the mRNA expression of CYP3A4, CYP3A5 and CYP1A1 under both culturing conditions. However, the mRNA exhibited by the $3-d$ cells for CYP3A4 is lower than in the 21-d model whereas it is the same for CYP1A1 and 3A5. Since the same clone was used in both culture systems, it can be suggested that the level of expression of the CYP3A4 is lower in the 3-d model and therefore inappropriate for testing its implication in drug metabolism. Engman et al. ${ }^{19)}$ showed that the TC7 cell line is easy inducible for its CYP3A4 and this property should be further evaluated since the intestinal metabolism of new 
chemical entities have to be evaluated using short term cultures.

Caco-2 cell monolayers are widely used for mechanistic studies to identify the transport pathway of drugs across the human intestinal epithelium. Since they differentiate in a single cell monolayer, they provide an easy model for mechanistic studies in contrast to other methods using ex vivo tissues (e.g., Ussing chambers). ${ }^{16,17,20,21)}$ Both AP-to-BL and BL-toAP transport of compounds with or without inhibitors can be performed to identify a transport mechanism though the cell monolayers, active or passive. In this base, we evaluated the carrier-mediated transport of the L-Phe in both models using a single concentration around the $K_{\mathrm{m}}$ value of each apical and basolateral transporter at $37^{\circ} \mathrm{C}$, since it was demonstrated by others that this compound is a specific substrate of the large neutral amino acid carrier. ${ }^{16)}$ In this study, the AP uptake was higher in the 21-d model (Table 3), showing that the expression of the L-Phe carrier is more active than those exhibited by the 3-d model. Furthermore, the expression of the apical uptake carrier was higher by 2-fold in the 21-d model. The non polarization in AP-to-BL and BL-to-AP transport is thus able to induce incorrect conclusions in mechanistic studies when the passage of the compounds is unknown. These results suggested that the 3-d model: (i) is not well differentiated and (ii) it use may be limited for studying active transport processes. Numerous carriers are expressed in Caco-2 cells with differing levels compared with the in vivo situation. ${ }^{22)}$ This study has to be followed up by evaluating other carriers expressed in Caco-2/TC7 cells to check wether the large neutral amino acid carrier expression is representative of global carrier-mediated expression in the 3-d model. In will also be interesting to further characterize this model depending on periode of culture length to identify the appropriate days of cell culture for transport and metabolic studies.

For passively mediated compounds, when the logarithm of apparent permeability values of each model was plotted against the fraction absorbed in humans, a reasonable sigmoid correlation was obtained in both cases (Fig. 4). In addition, a good linear correlation was found between the two models $(n=10)\left(r^{2}=0.98 ; p<0.01\right)$ with the Papp $(\mathrm{cm} / \mathrm{s})$ values of all tested compounds (Fig. 5). The potential of rank ordering of compounds was evaluated by the ratio between high (e.g., caffeine) and low (e.g., mannitol) permeable compounds. The caffeine/mannitol ratios were close to 80 and 360 , respectively, in the $3-\mathrm{d}$ and $21-\mathrm{d}$ models. This suggested their predictive usefulness to assess the oral absorption of new chemical entities. However, some discrepancies were found with previous work. ${ }^{9,11)}$ Actually, Liang et al. $^{11)}$ found a ratio between highly and poorly permeable compounds (caffeine/mannitol Papp $(\mathrm{cm} / \mathrm{s})$ ratio=4) across the $3-\mathrm{d}$ parental model and suggested that this model is not usable for rank ordering of passively absorbed compounds. In contrast, Chong et al. ${ }^{9)}$ presented in their study a caffeine/mannitol ratio close to 6 described to be compatible with a high potential of rank ordering of compounds. In our study, the ratio caffeine/mannitol was 80 in serum free media TC7 cells. This ratio suggested the applicability of the $3-\mathrm{d} / \mathrm{TC} 7$ model for classifying drug permeability under the Biopharmaceutical Classification System ${ }^{23}$ ) with higher potential of rank ordering than those obtained with short-term parental Caco-2 cell models.

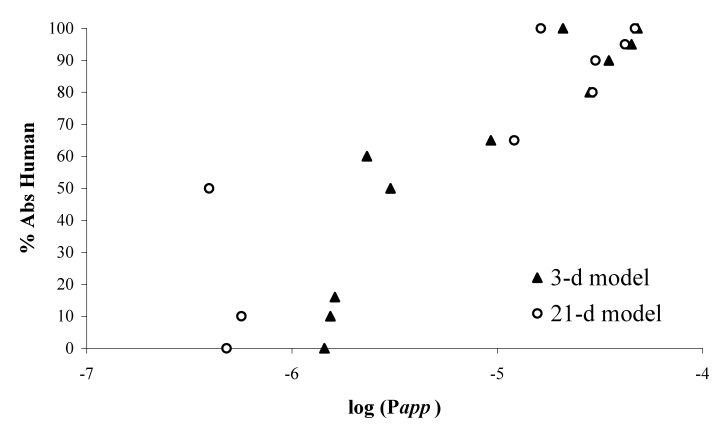

Fig. 4. Correlation between in Vivo Permeability and in Vitro Apparent Permeability Values Obtained with the 21- and the 3-d Caco-2/TC7 Cell Monolayers

Each data point represents the mean value of three to six experiments.

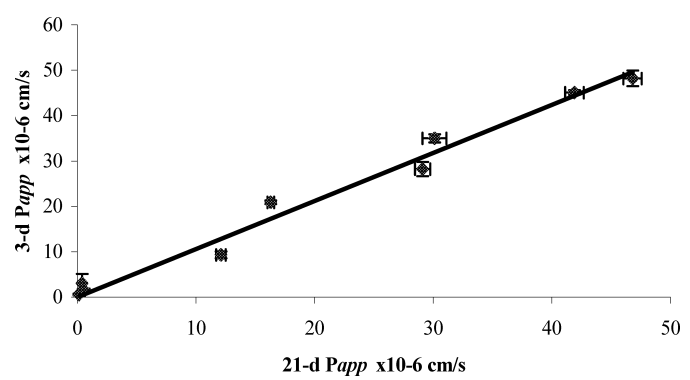

Fig. 5. Correlation between the Logarithm of Apparent Permeability Values (Papp $\mathrm{cm} / \mathrm{s})$ across the 3-d and the 21-d Caco-2/TC7 Cell Monolayers

The straight line represents the linear regression equation $y=1.06 x \quad\left(r^{2}=0.98\right.$, $p<0.01$ ). Each data point represents the mean value of three to six experiments.

\section{CONCLUSIONS}

In this study, using TC7 cells cultured in conventional and accelerated culture media, we found that the level of maturation of the 3-d model was lower in both morphologic and biochemical aspects. This indicated the limited application of TC7/3-d cultures for study of the impact of metabolism in drug absorption. The expression of carrier-mediated transport also appeared too low to evaluate the potential of absorption of compounds actively absorbed. However, using the TC7 cell line without fetal calf serum, we found comparable results between the $3-d$ and the $21-d$ culture systems for passively absorbed compounds with high potential of rank ordering of compounds. The in vitro/in vivo correlations obtained with both systems suggested that they are valuable tools to determine the absorption of passively permeable compounds. They are less time consuming and have increased labor efficiency when the $3-\mathrm{d}$ model is used.

\section{REFERENCES}

1) Artursson P., J. Pharm. Sci., 79, 476-482 (1990).

2) Artursson P., Karlsson J., Biochem. Biophys. Res. Commun., 175, 880 -885 (1991).

3) Irvine J. D., Takahashi L., Lockhart K., Cheong J., Tolan J. W., Selick H. E., Grove J. R., J. Pharm. Sci., 88, 28-33 (1999).

4) Pontier C., Pachot J., Botham R., Lenfant B., Arnaud P., J. Pharm. Sci., 90, 1608-1619 (2001).

5) Engle M. J., Goetz G. S., Alpers D. H., J. Cell. Physiol., 174, $362-$ 369 (1998).

6) Raeissi S. D., Guo Z., Dobson G. L., Artursson P., Hidalgo I. J., Pharm. Res., 14, 1019-1025 (1997).

7) Raeissi S. D., Hidalgo I. J., Segura-aguilar J., Artursson P., Pharm. 
Res., 16, 625-632 (1999).

8) Caro I., Boulenc X., Rousset M., Meunier V., Bourrié M., Julian B., Joyeux H., Roques C., Berger Y., Zweibaum A., Fabre G., Int. J. Pharm., 116, 147-158 (1995).

9) Chong S., Dando S. A., Morrison R. A., Pharm. Res., 14, 1835-1837 (1997).

10) Lentz K. A., Hayashi J., Luciano L. J., Polly J. E., Int. J. Pharm., 200, $41-51$ (2000).

11) Liang E., Chessic K., Yazdanian M., J. Pharm. Sci., 89, 336-345 (2000).

12) Yamashita S., Konishi K., Yamazaki Y., Taki Y., Sakane T., Sezaki H., Furuyama Y., J. Pharm. Sci., 91, 669-679 (2002).

13) Collett A., Sims E., Walker D., He Y.-L., Ayrton J., Rowland M., Warhurst G., Pharm. Res., 13, 216-221 (1996).

14) Eicholtz A., Biochi. Biophys. Acta, 135, 39-49 (1967).

15) Pollard H. B., Menard R., Brandt H. A., Pazoles C. J., Creutz C. E.,
Ramu A., Anal. Biochem., 86, 761-763 (1978).

16) Hidalgo I. J., Borchardt R. T., Biochim. Biophys. Acta, 1028, 25-30 (1990).

17) Lee C.-P., de Vrueh R. L. A., Smith P. L., Adv. Drug Del. Rev., 23, 47-62 (1997).

18) Chantret I., Barbat A., Dussaulx E., Brattain M. G., Zweibaum A., Cancer Res., 48, 1936-1942 (1998).

19) Engman H. A., Lennernas H., Taipalnsiuu J., Otter C., Leidvik B., Artursson P., J. Pharm. Sci., 90, 1736-1751 (2001).

20) Hu M., Borchardt T., Pharm. Res., 7, 1313-1319 (1990).

21) Cogburn J. N., Donovan M. G., Schasteen C. S., Pharm. Res., 8, 210 216 (1991).

22) Delie F., Rubas W., Crit. Rev. Ther. Drug Car. Syst., 14, 221-286 (1997).

23) Amidon G. L., Lennernäs H., Shah V. P., Crison J. R., Pharm. Res., 12, $413-420(1995)$. 